\title{
Corrosion inhibition of Elektron WE43 magnesium alloy in $\mathrm{NaCl}$ solution
}

\author{
A.A. Chirkunov ${ }^{1}$ and M.L. Zheludkevich ${ }^{2}$ \\ ${ }^{1}$ A.N. Frumkin Institute of Physical Chemistry and Electrochemistry, Russian Academy \\ of Sciences, Leninsky pr. 31, Moscow, 119071 Russian Federation \\ ${ }^{2}$ Magnesium Innovation Centre MagIC, Helmholtz-Zentrum Geesthacht, Max-Planck \\ Straße 1, Geesthacht, 21502 Germany \\ E-mail:chirkunov@inbox.ru
}

\begin{abstract}
Magnesium alloys have a wide range of applications but suffer low corrosion resistance. One of the most accessible ways to protect metals from corrosion, which can also be combined with other methods, is the use of corrosion inhibitors. The effect of 1,2,3benzotriazole, 5-chloro-1,2,3-benzotriazole and sodium dioctyl phosphate on the corrosion of Elektron WE43 magnesium alloy in $0.05 \mathrm{M} \mathrm{NaCl}$ solution was studied using polarization and EIS measurements. Azoles do not exhibit the inhibitive action towards the WE43 alloy, but they slightly reduce the barrier effect of the film of corrosion products. Sodium dioctyl phosphate (DOP) is an effective inhibitor due to its anionic nature. It mainly inhibits the anodic dissolution of the alloy and has a slight effect on the cathodic process. DOP enhances the protective effect in time due to improvement of protective films. An increase in DOP concentration depresses the anodic dissolution of the alloy as well as the local depassivation, which is characterized by a displacement of the pitting potential in the positive direction. Scanning vibrating electrode technique (SVET) measurements confirmed the effectiveness of DOP as a corrosion inhibitor for Electron WE43 alloy.
\end{abstract}

Received: March 3, 2018. Published: August 27, 2018

doi: $\underline{10.17675 / 2305-6894-2018-7-3-8}$

Keywords: magnesium alloy, corrosion inhibitors, polarization measurements, EIS.

\section{Introduction}

Magnesium alloys have an important combination of properties: low density, high strength and good machinability, which makes them attractive for application in the automotive and aircraft industries, as well as in the space industry. The disadvantage of magnesium alloys is high reactivity and, as a result, susceptibility to corrosion. The low corrosion resistance of magnesium and its alloys determines the need for protection from environmental influences. The conventional method of surface treatment of magnesium and its alloys with chromates is currently unacceptable due to environmental and toxicological restrictions, and therefore it becomes urgent to look for other methods of protection, in particular, the 
use of corrosion inhibitors. Inhibitors can also be used as a supplement to other corrosion protection methods, for example, conversion coatings and paints, acting as the agents for healing the defects of the coating.

Various classes of chemical compounds are known as corrosion inhibitors for magnesium and light alloys: carboxylic acid salts [1-3], sulfonates, 8-hydroxyquinoline [2, 4], azoles [5, 6], cerium compounds [7, 8], Schiff bases [9], and polyamino acids [10]. The compounds capable of forming insoluble complexes or salts with magnesium cations are of particular interest. In the first place, heterocyclic compounds like azoles and anionic surfactants can be noted. For example, 8-hydroxyquinoline enhanced the protective ability of sol-gel coatings on the AZ31 alloy due to the formation of sparingly soluble complexes with magnesium cations [11]; 1,2,4-triazole also showed high inhibition activity [12,13].

Triazoles containing various substituents may be of interest as the corrosion inhibitors for magnesium and its alloys. Substituents can significantly affect the acid-base properties, hydrophobicity, and hence the adsorption and inhibition activity of heterocyclic molecules. For example, the efficiency of inhibition of copper corrosion in $0.1 \mathrm{M} \mathrm{NaCl}$ by substituted benzotriazoles (BTA) gave the following sequence: 5-methyl-BTA $<5$-chloro-BTA $<5-n$ hexyl-BTA [14]. 5-Pentyl-BTA and 5-chloro-BTA exceed BTA in adsorption and protective properties for copper in a neutral borate buffer solution [15]. Inhibition of anodic dissolution of copper and zinc by substituted benzimidazoles has shown the dependence of protective effect on $\sigma$-constants (Hammett constants) of substituents [16].

Various anionic surfactants are known as effective and versatile corrosion inhibitors capable of slowing down the active dissolution and local depassivation of metals. Anions of carboxylic acids show a protective effect on various metals and alloys [16] and inhibit the corrosion of magnesium due to the formation of sparingly soluble hydrophobic compounds with its cations. Esters of phosphoric acid, in particular, dialkylphosphates, are noteworthy. Similarly to carboxylates, they contain an anionic functional group and a hydrophobic part of the molecule and are able to act as corrosion inhibitors for zinc, aluminum alloys and steel $[17,18]$. It can be expected that dialkyl phosphates would have protective properties toward magnesium alloys.

The present paper discusses the influence of BTA, 5-chloroBTA and sodium dioctyl phosphate on the corrosion and electrochemical behavior of Elektron WE43 magnesium alloy.

\section{Experimental}

Elektron WE43 alloy plates were used in the experiments. The composition of the alloy is as follows: yttrium 3.7-4.3\%; rare earth metals $2.3-3.5 \%$; zirconium $0.2 \%$; magnesium the rest. For electrochemical measurements electrodes were armored in epoxy resin, with a working surface of $1 \mathrm{~cm}^{2} .0 .05 \mathrm{M} \mathrm{NaCl}$ solution was used as the corrosive medium. 1,2,3Benzotriazole (BTA), 5-chloro-1,2,3-benzotriazole (Cl-BTA) and sodium dioctyl phosphate (DOP) were studied as inhibitors. BTA and Cl-BTA do not change the $\mathrm{pH}$ of the solution (5.6). Addition of $5 \mathrm{mM}$ DOP increased the solution $\mathrm{pH}$ to 6.3. 
The experiments were carried out at a temperature of $20^{\circ} \mathrm{C}$ with natural aeration. Polarization potentiodynamic measurements were performed at a potential scanning rate of $0.2 \mathrm{mV} / \mathrm{s}$ after the free corrosion potential stabilized (1 hour). Electrochemical impedance spectra (EIS) were obtained at the free corrosion potential in the frequency range of $10^{5}-$ $10^{-2} \mathrm{~Hz}$ and with a potential amplitude of $10 \mathrm{mV}$. Potentials were measured against a saturated calomel electrode. The EIS simulation was carried out using ZView software.

Measurements using the scanning vibrating electrode technique (SVET) were performed on Applicable Electronics equipment with ASET software.

\section{Results and Discussion}

The data on the measurement of the free corrosion potential $E_{\text {cor }}$ show (Figure 1) that a constant value is set in approximately $1 \mathrm{~h}$. It shifts to more negative values in solutions containing the tested compounds in comparison with the blank solution $(-1.72 \mathrm{~V})$. The most negative $E_{\text {cor }}$ values were obtained in the presence of BTA and Cl-BTA.

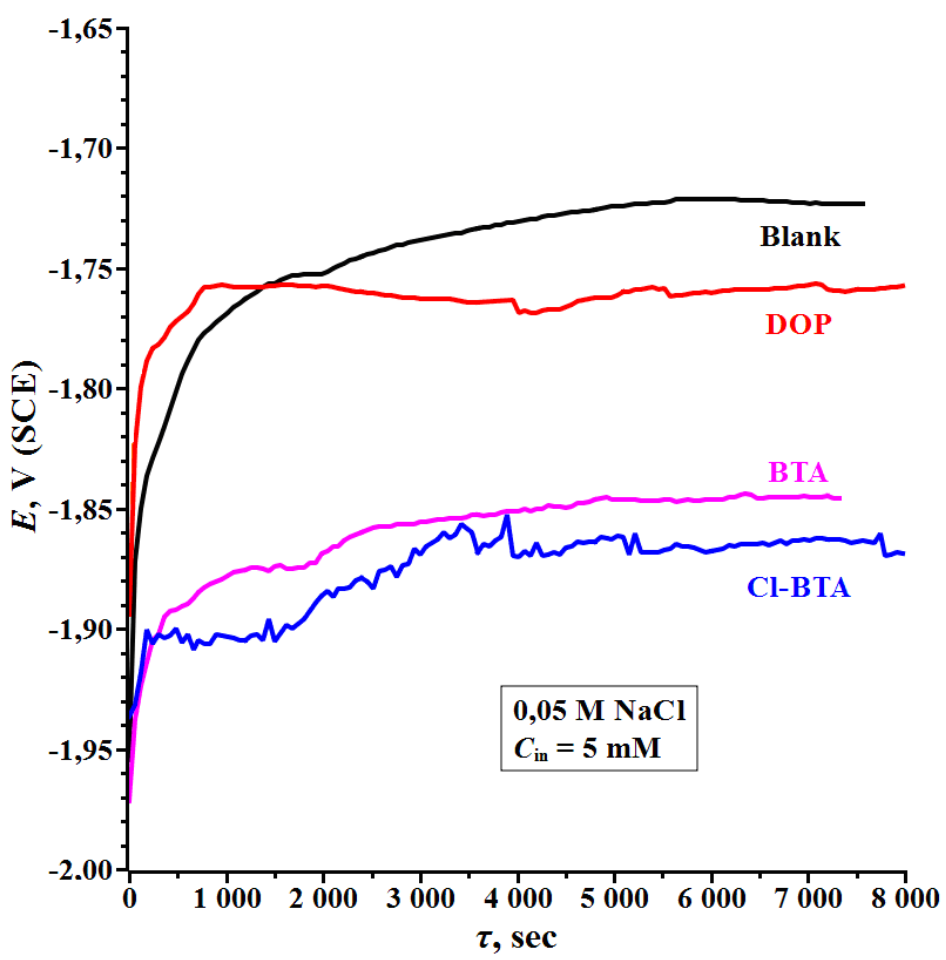

Figure 1. The dependence of $E_{\mathrm{cor}}$ of WE43 on the time of immersion in $0.05 \mathrm{M} \mathrm{NaCl}$.

The results of polarization potentiodynamic measurements after exposure of WE43 electrodes in solutions of the tested compounds demonstrate a slight effect of BTA or ClBTA and significant inhibition of the alloy anodic dissolution by DOP (Figure 2). When the potential is shifted to the anodic region, active dissolution is observed in the presence of azoles, but with DOP a small region of independence of the current density on the potential followed by a sharp increase in current caused by localized dissolution of the alloy occurs. The effect of the additives on the cathodic process is weak. 


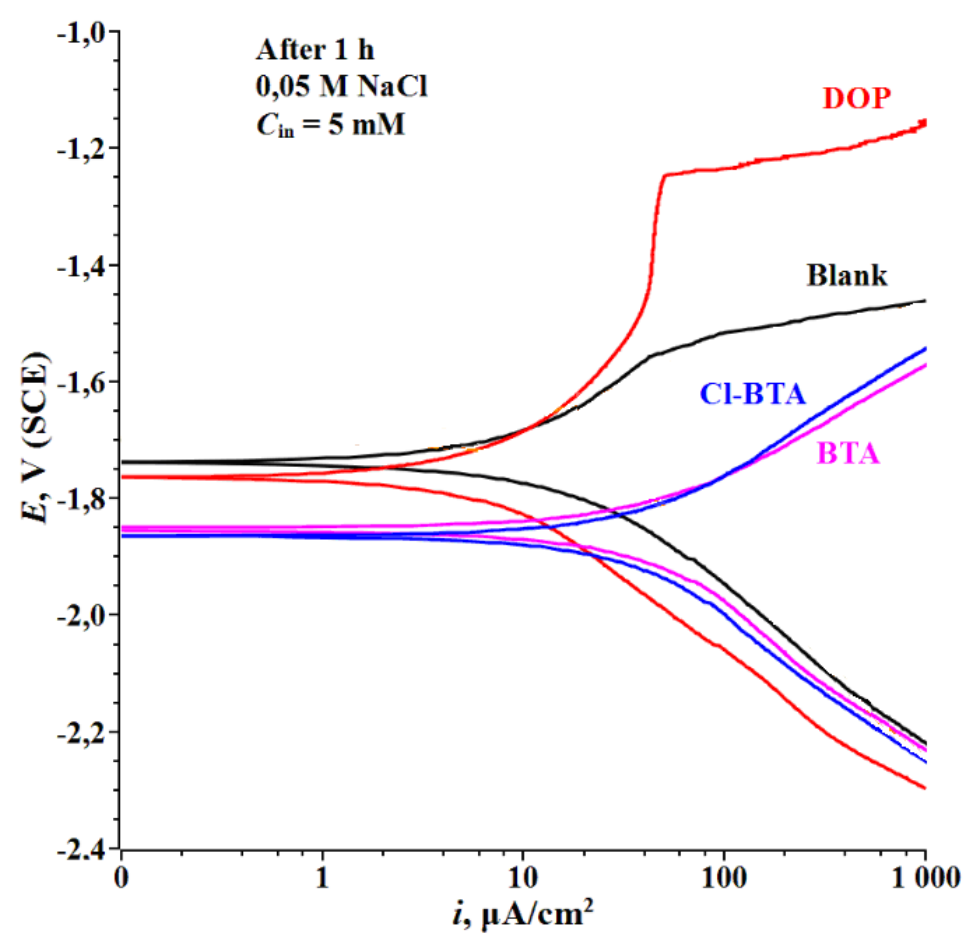

Figure 2. Anodic and cathodic polarization curves of WE43 magnesium alloy after $1 \mathrm{~h}$ of immersion in $0.05 \mathrm{M} \mathrm{NaCl}$ with $5 \mathrm{mM}$ of additives.

DOP is the most effective inhibitor among the compounds studied, which is quite expected taking into account the anionic nature and the presence of hydrophobic alkyls in the molecule. Probably, DOP is able to form hardly soluble salts with magnesium cations that create a protective film on the alloy surface, similarly to carboxylates. Increasing the DOP concentration depresses the anodic dissolution of the alloy as well as its local depassivation characterized by a displacement of pitting potential $E_{\mathrm{pt}}$ in the positive direction (Figure 3). The inhibition effect of DOP increases with the time of immersion of the electrode in the solution for up to $24 \mathrm{~h}$ : the film breakdown potential at $C_{\mathrm{DOP}}=5 \mathrm{mM}$ shifts to $-0.8 \mathrm{~V}$, i.e., by more than $0.4 \mathrm{~V}$ in comparison to the value obtained after immersion for $1 \mathrm{~h}$ (Figure 4). The anodic polarizability of the alloy in the blank solution also increases. This indicates the effectiveness of the inhibitor and the formation of denser protective layers with time.

The electrochemical impedance spectra (EIS) of WE43 obtained after 1 hour of exposure in $\mathrm{NaCl}$ solutions without additives or in the presence of $5 \mathrm{mM}$ of the tested compounds are shown in Figure 5.

The results of EIS measurements were simulated using the equivalent electric circuits (EEC) shown in Figure 6. Figure 6a shows the EEC for the blank and BTA or Cl-BTA solutions, and Figure $6 \mathrm{~b}$ shows the one for the DOP solution. 


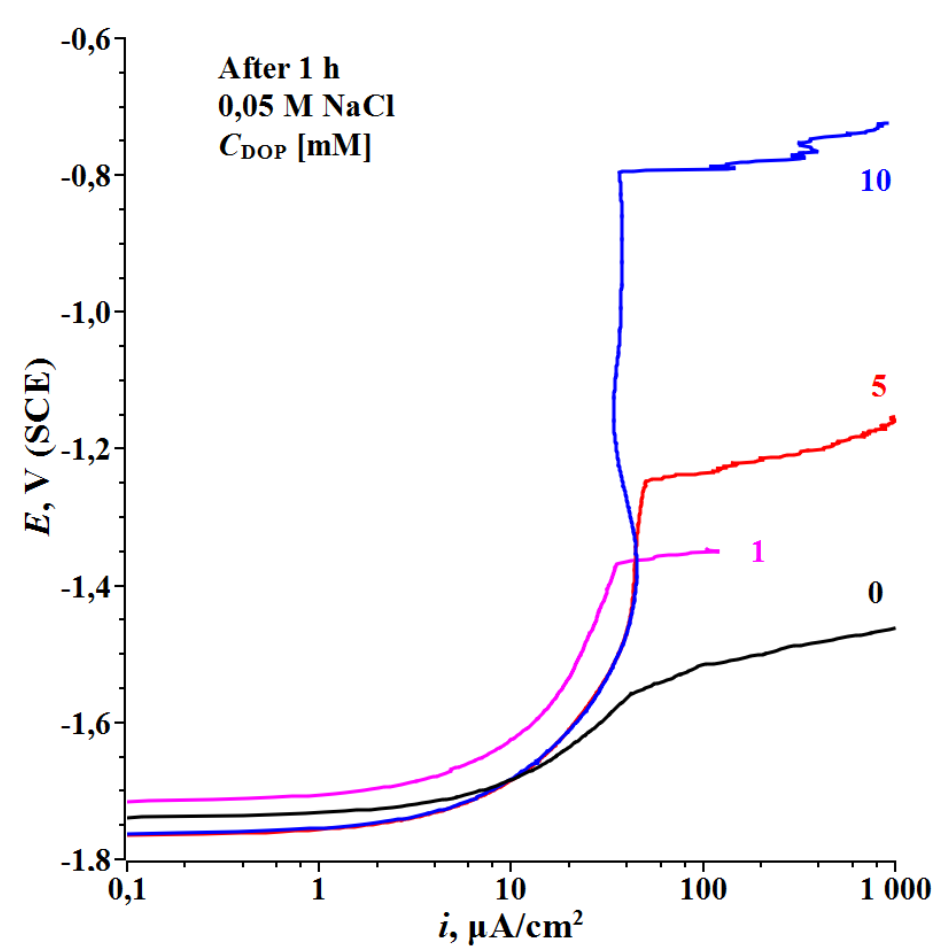

Figure 3. Anodic polarization curves of WE43 magnesium alloy after $1 \mathrm{~h}$ of immersion in $0.05 \mathrm{M} \mathrm{NaCl}$ in the presence of DOP $(\mathrm{mM})$.

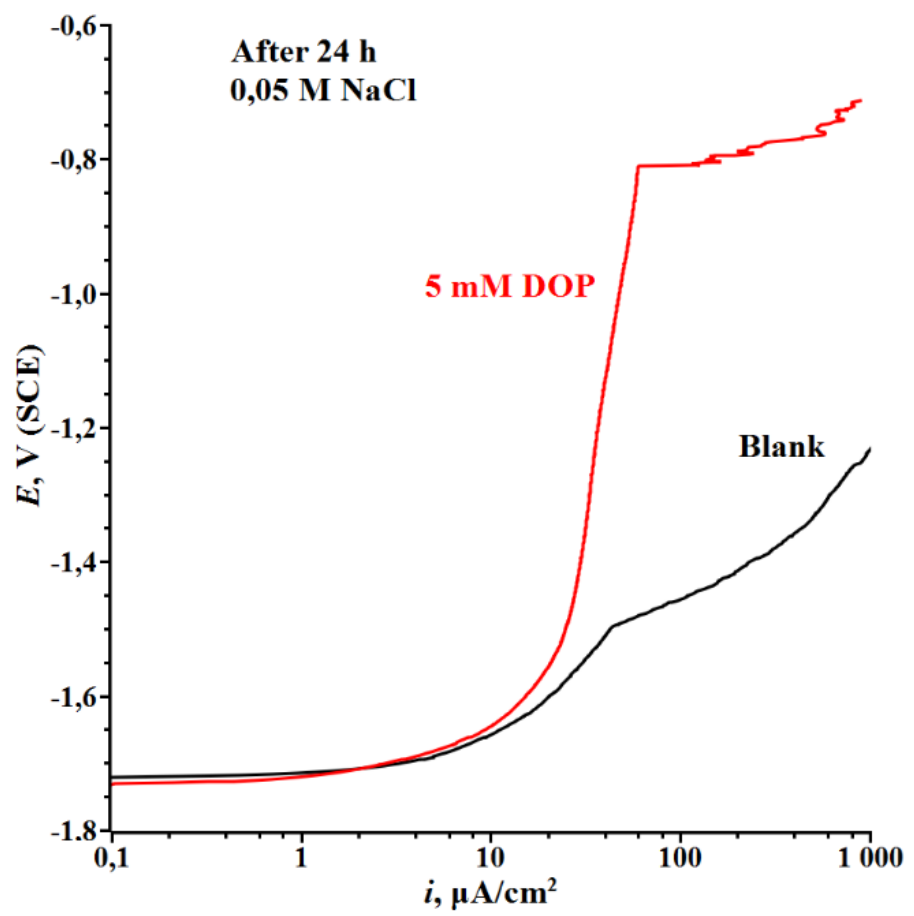

Figure 4. Anodic polarization curves of WE43 magnesium alloy after $24 \mathrm{~h}$ of immersion in $0.05 \mathrm{M} \mathrm{NaCl}$ in the presence of $5 \mathrm{mM}$ DOP. 


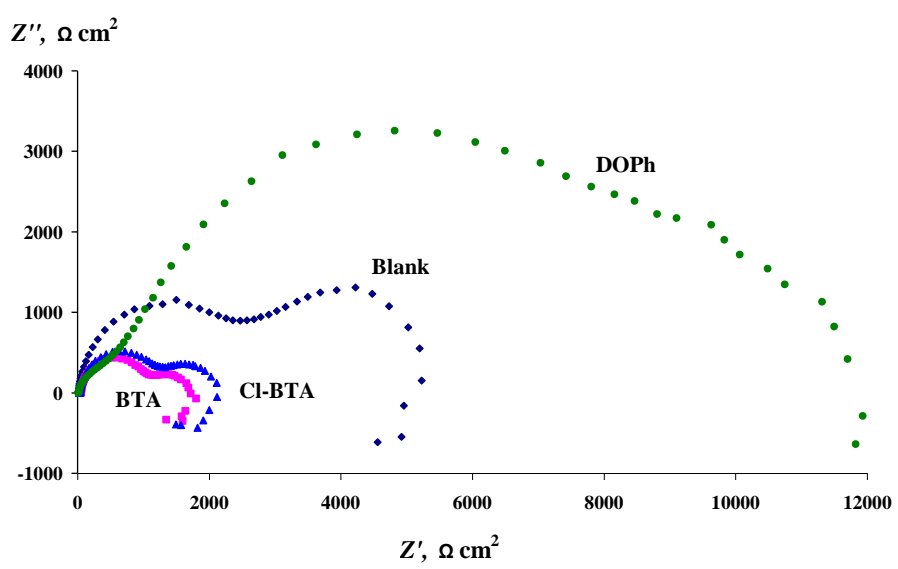

$a$
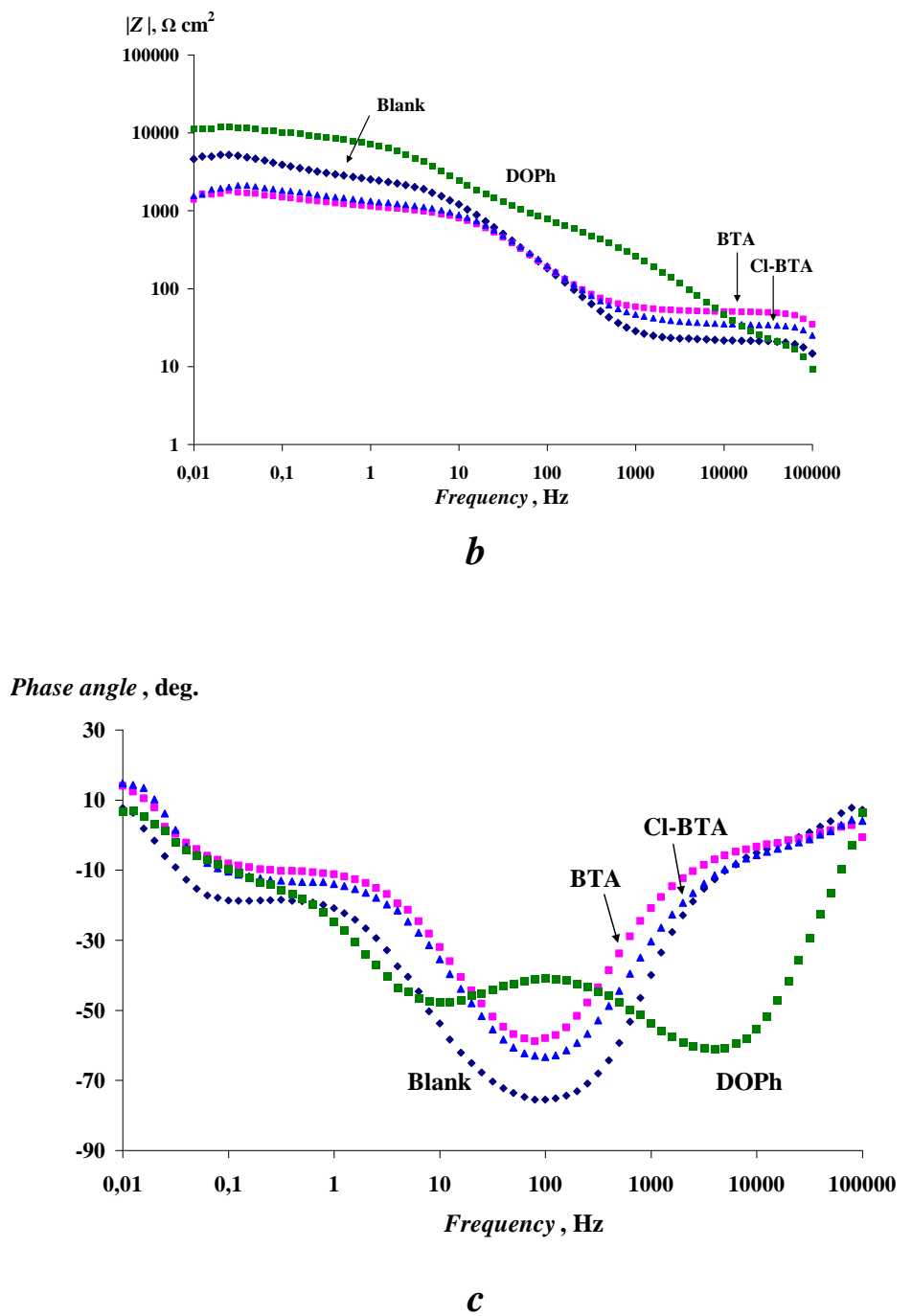

Figure 5. EIS spectra obtained for WE43 magnesium alloy after $1 \mathrm{~h}$ of immersion in $0.05 \mathrm{M}$ $\mathrm{NaCl}$ without or with $5 \mathrm{mM}$ of tested compounds. 


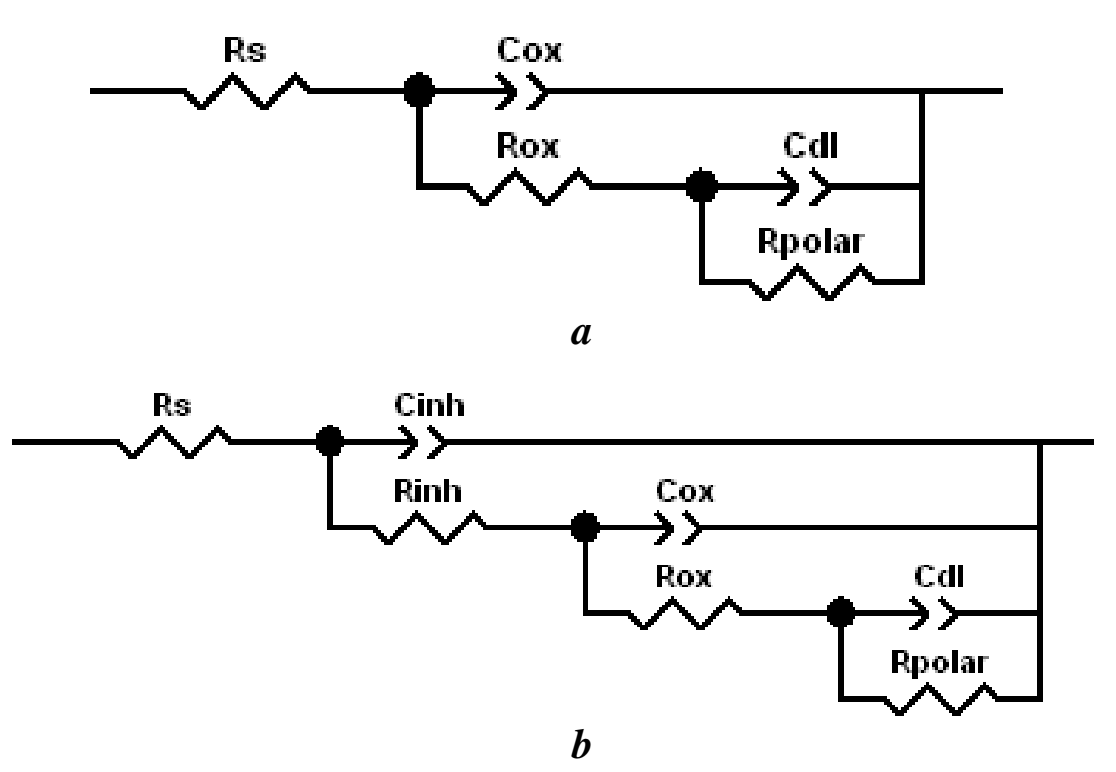

Figure 6. EEC used to simulate EIS of WE43 magnesium alloy obtained in $0.05 \mathrm{M} \mathrm{NaCl}$ containing BTA or Cl-BTA $(a)$ and DOPh $(b)$.

$R_{\mathrm{S}}$ corresponds to the electrical resistance of the solution, $R_{\mathrm{ox}}$ and $C_{\mathrm{ox}}$ - to the resistance and capacitance of the oxide film, $R_{\mathrm{inh}}$ and $C_{\mathrm{inh}}-$ to the resistance and capacitance of the inhibitor layer, $C_{\mathrm{dl}}$ - to the double layer capacitance, and $R_{\text {polar }}$ is the polarization resistance.

In the case of electrolyte with or without addition of BTA and Cl-BTA, the spectra are characterized by the presence of two capacitive semicircles (Figure 5a). The low-frequency impedance can be used as a measure of corrosive activity. It follows from Figure $5 b$ that the minimum values of the low-frequency impedance observed for WE43 immersed in $\mathrm{NaCl}$ solutions containing $5 \mathrm{mM}$ BTA or Cl-BTA are even smaller than those in the blank electrolyte. The presence of BTA and Cl-BTA in the corrosive medium leads to a decrease in the resistance of corrosion products $\left(R_{\mathrm{ox}}\right)$ in comparison with the blank electrolyte (Table 1). At the same time, $R_{\mathrm{ox}}$ significantly increases in the presence of DOP, which indicates the stabilization of the oxide-hydroxide layer by the inhibitor. In addition, a region corresponding to the contribution of the adsorbed inhibitor film appears in the EIS diagrams at low frequencies.

According to the polarization and EIS measurements, BTA and Cl-BTA do not show an inhibitive activity toward the WE43 alloy. At the same time, the surface activity of DOP provides a significant inhibitive effect.

The results obtained with increasing the time of immersion of a WE43 electrode in solution are shown in Figure 7 and in Table 2. During the first day the corrosion activity of the alloy in the blank electrolyte decreases due to the formation of a dense film of corrosion products, however, on increasing the time to 14 days the film resistance decreases. The presence of DOP in the solution leads to an increase in the resistances $R_{\text {inh }}$ and $R_{\mathrm{ox}}$ with time, which indicates the gradual formation of more perfect protective films. 
Table 1. The calculated parameters of EEC for WE43 after $1 \mathrm{~h}$ of immersion in $0.05 \mathrm{M} \mathrm{NaCl}$ without or with $5 \mathrm{mM}$ of the tested compounds.

\begin{tabular}{ccccc}
\hline Parameter & Blank & BTA & Cl-BTA & DOP \\
\hline$R_{\mathrm{S}}$ & 20.51 & 48.43 & 33.44 & 17.08 \\
$C_{\mathrm{inh}}-T$ & - & - & - & $9.6114 \mathrm{E}-7$ \\
$C_{\mathrm{inh}}-P$ & - & - & - & 0.9249 \\
$R_{\mathrm{inh}}$ & - & - & - & 544.3 \\
$C_{\mathrm{ox}}-T$ & $1.291 \mathrm{E}-5$ & $1.8137 \mathrm{E}-5$ & $1.8133 \mathrm{E}-5$ & $1.897 \mathrm{E}-5$ \\
$C_{\mathrm{ox}}-P$ & 0.94922 & 0.89495 & 0.88188 & 0.7185 \\
$R_{\mathrm{ox}}$ & 2351 & 1016 & 1229 & 9865 \\
$C_{\mathrm{dl}}-T$ & 0.00042785 & 0.0015016 & 0.00090878 & 0.0014114 \\
$C_{\mathrm{dl}}-P$ & 0.82146 & 0.71122 & 0.81109 & 1.11 \\
$R_{\mathrm{polar}}$ & 2833 & 650 & 871 & 1354 \\
\hline
\end{tabular}

Table 2. The calculated parameters of EEC for WE43 after $1 \mathrm{~h}, 1$ day or 14 days of immersion in $0.05 \mathrm{M}$ $\mathrm{NaCl}$.

\begin{tabular}{c|ccc|ccc}
\hline \multirow{2}{*}{ Parameter } & \multicolumn{3}{|c|}{ Blank } & \multicolumn{3}{c}{$\mathbf{5}$ mM DOP } \\
\cline { 2 - 7 } & $\mathbf{1 ~ h}$ & $\mathbf{1 ~ d}$ & $\mathbf{1 4 ~ d}$ & $\mathbf{1 ~ h}$ & $\mathbf{1 ~ d}$ & $\mathbf{1 4 ~ d}$ \\
\hline$R_{\mathrm{s}}$ & 20.51 & 16.6 & 45.87 & 17.08 & 27.18 & 20.12 \\
$C_{\mathrm{inh}}-T$ & - & - & - & $9.6114 \mathrm{E}-7$ & $2.3649 \mathrm{E}-6$ & $7.7522 \mathrm{E}-6$ \\
$C_{\mathrm{inh}}-P$ & - & - & - & 0.9249 & 0.81773 & 0.58733 \\
$R_{\mathrm{inh}}$ & - & - & - & 544.3 & 839 & 1150 \\
$C_{\mathrm{ox}}-T$ & $1.291 \mathrm{E}-5$ & $1.4955 \mathrm{E}-5$ & $4.2926 \mathrm{E}-5$ & $1.897 \mathrm{E}-5$ & $1.5278 \mathrm{E}-5$ & $2.1932 \mathrm{E}-5$ \\
$C_{\mathrm{ox}}-P$ & 0.94922 & 0.9217 & 0.83296 & 0.7185 & 0.76784 & 0.80416 \\
$R_{\mathrm{ox}}$ & 2351 & 5705 & 2975 & 9865 & 14869 & 31504 \\
$C_{\mathrm{dl}}-T$ & 0.00042785 & 0.00044135 & 0.001738 & 0.0014114 & 0.0011668 & 0.049734 \\
$C_{\mathrm{dl}}-P$ & 0.82146 & 0.84295 & 0.93042 & 1.11 & 1.047 & 1.546 \\
$R_{\text {polar }}$ & 2833 & 3813 & 1032 & 1354 & 4398 & 1369 \\
\hline
\end{tabular}



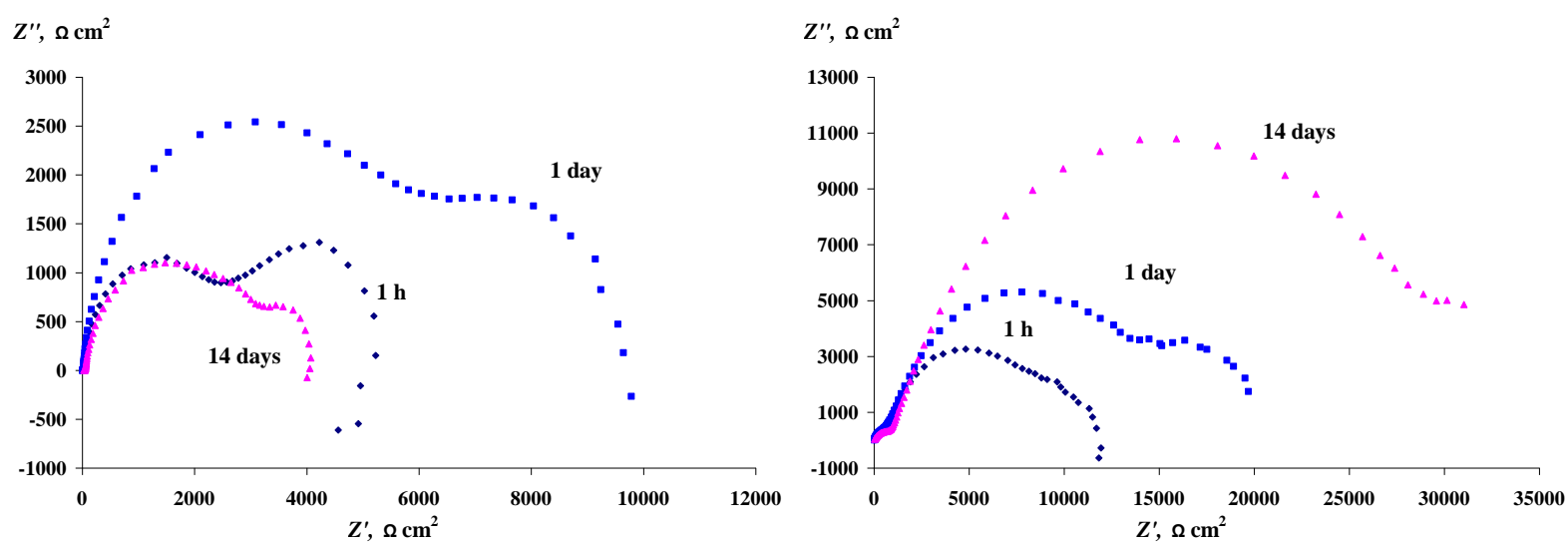

$a$
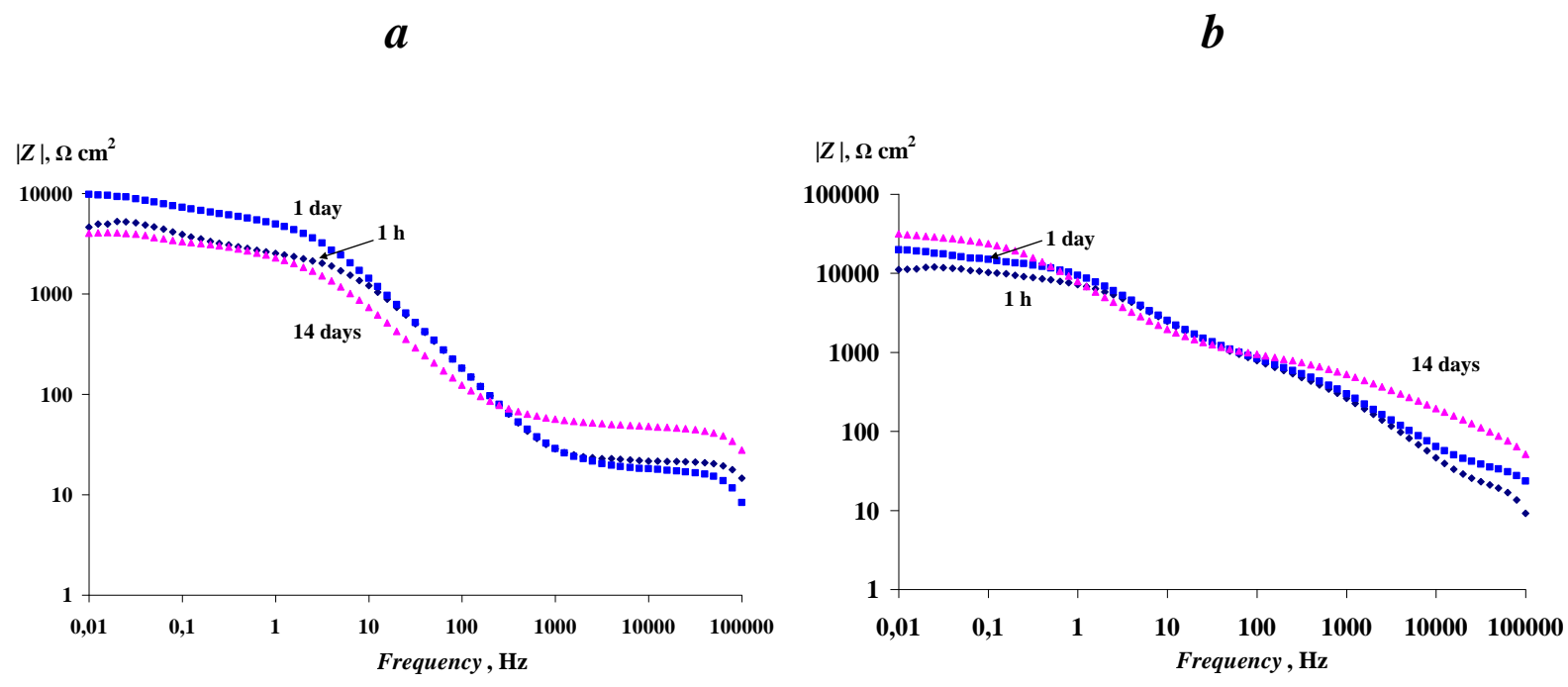

$c$

\section{$d$}

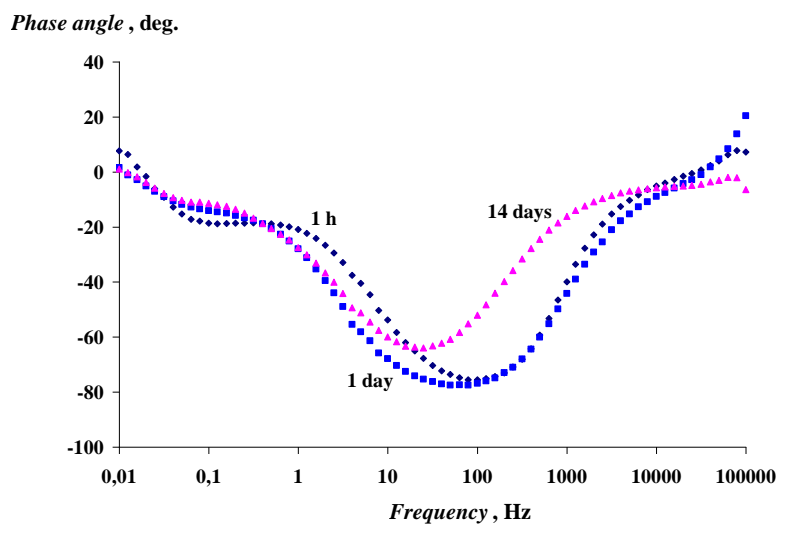

Phase angle, deg.

\section{$\boldsymbol{e}$}
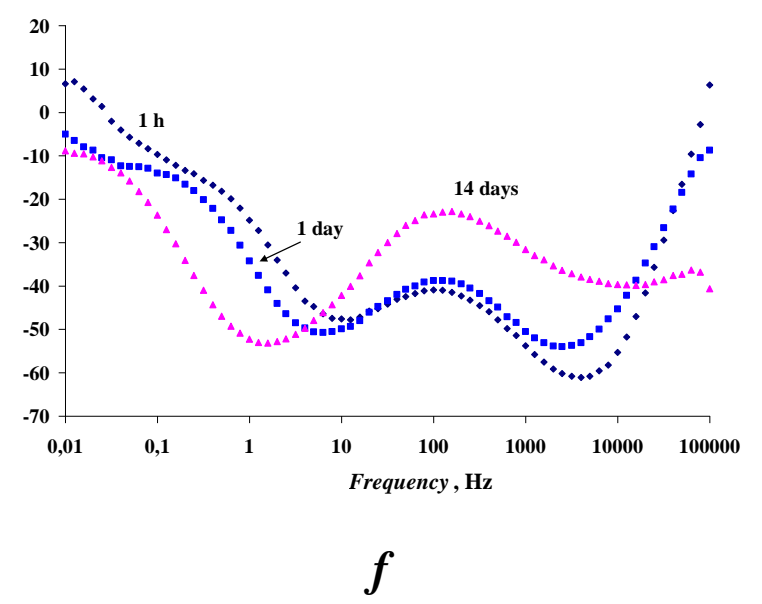

Figure 7. EIS spectra obtained for WE43 magnesium alloy after $1 \mathrm{~h}, 1$ day or 14 days of immersion in $0.05 \mathrm{M} \mathrm{NaCl}$ without $(a, b, c)$ or with $5 \mathrm{mM}$ of DOP $(d, e, f)$. 
The appearance of alloy WE43 samples after immersion in the solutions also indicates the tested compounds manifest different effects on the corrosion process (Figure 8).

1 d

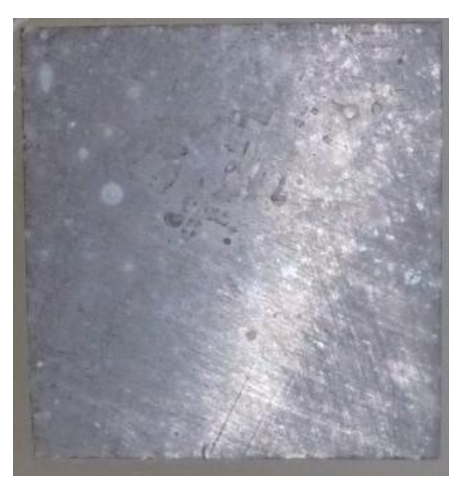

$0.05 \mathrm{M}$

$\mathrm{NaCl}$

$0.05 \mathrm{M}$

$\mathrm{NaCl}$

$5 \mathrm{MM}$

DOP

$0.05 \mathrm{M}$

$\mathrm{NaCl}$

$5 \mathrm{MM}$

BTA

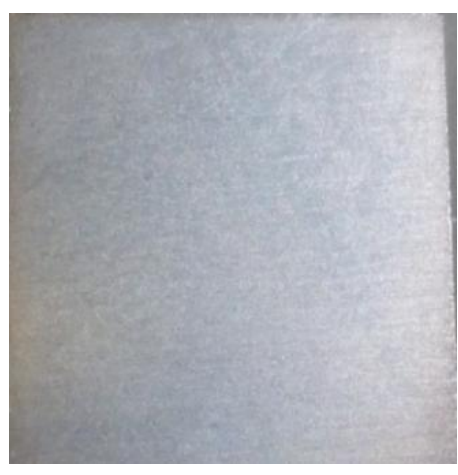

$14 \mathrm{~d}$
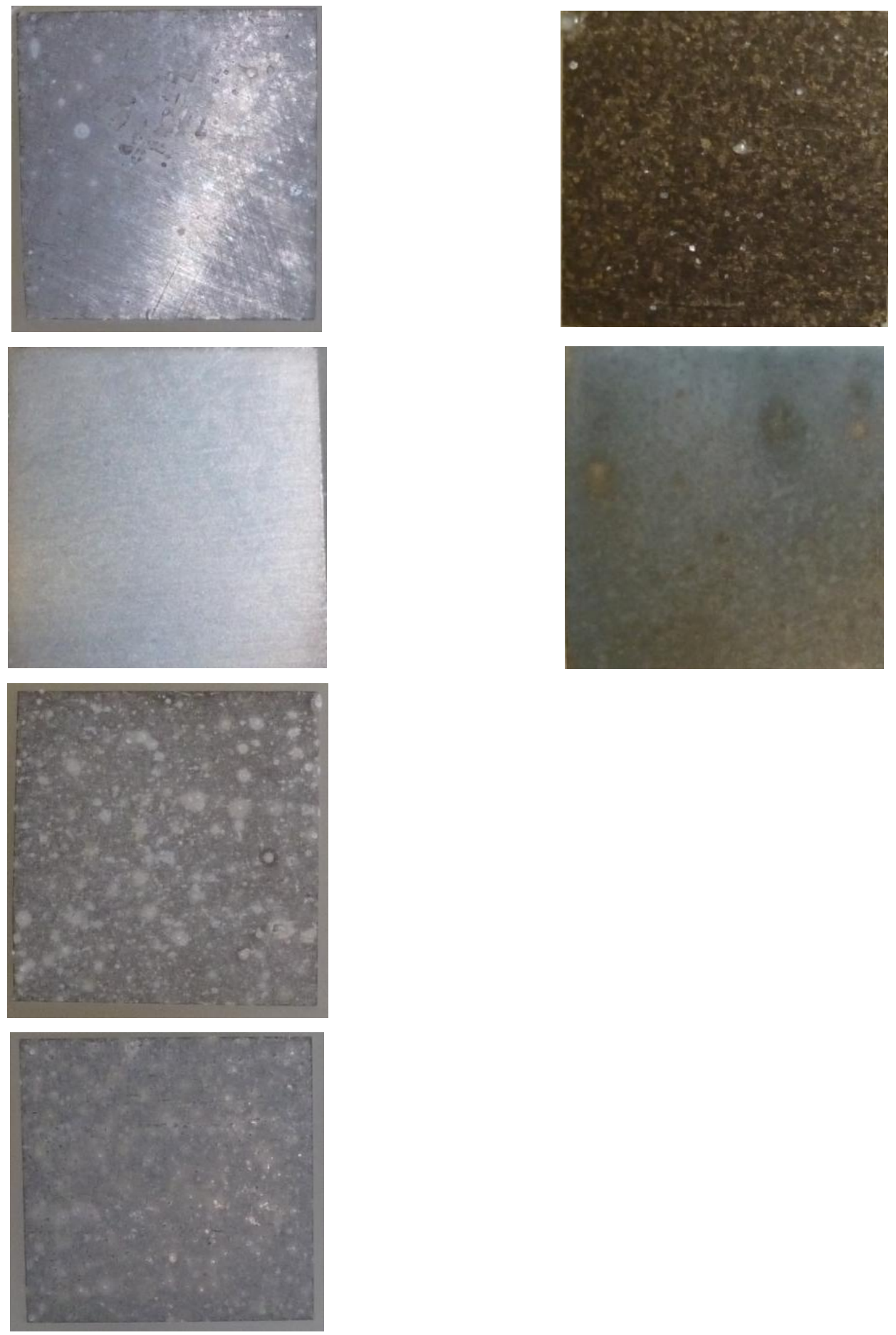

$0.05 \mathrm{M}$

$\mathrm{NaCl}$

$5 \mathrm{MM}$

Cl-BTA

Figure 8. Photos of WE43 specimens after exposure in blank and inhibited solutions. 
After 1 day, the localized areas of corrosion appeared on the surface of the alloy immersed in the uninhibited solution, while corrosion was even more expressed in the presence of $5 \mathrm{mM}$ BTA or Cl-BTA. Bubbles of evolved hydrogen were observed on the surface of the samples. Under the same conditions, DOP proved to be an effective inhibitor. During the first $24 \mathrm{~h}$ there was a gradual decrease in the amount of evolved hydrogen, up to complete disappearance of the bubbles from the surface, and corrosion was not observed, either. After 2 weeks of testing in the solution without any inhibitor, the surface of the samples was completely covered with a film of corrosion products, on which local dissolution of the alloy was observed. In the presence of $5 \mathrm{mM}$ DOP, only tarnishing of the surface and minor traces of corrosion were found.

The results obtained by the SVET method (Figure 9) also confirm the effectiveness of DOP as an inhibitor of magnesium alloy corrosion. Over time, in the presence of DOP, the amount of hydrogen bubbles released decreases, until their complete disappearance, the surface of the sample tarnishes slightly, but there are no visible corrosion lesions on it. The values of the corrosion current in the presence of the inhibitor are much smaller than in the blank electrolyte, although in both cases they decrease with time. In a solution without an inhibitor, the localization of corrosion processes on the alloy surface is more expressed, while in a solution containing $5 \mathrm{mM}$ DOP, the local dissolution is suppressed almost completely. As a result, DOP is an effective inhibitor that promotes the formation of protective films on the surface of the magnesium alloy and reduces the rate of its local dissolution.

\section{Conclusions}

1,2,3-Benzotriazole and 5-chloro-1,2,3-benzotriazole do not have a protective effect on the WE43 alloy in $0.05 \mathrm{M} \mathrm{NaCl}$ solution and adversely affect the barrier properties of films of corrosion products. Under the same conditions, sodium dioctyl phosphate exhibits a high inhibition ability, mainly suppressing the anodic partial electrode process. Its protective effect is enhanced with time, apparently due to the formation of sparingly soluble compounds with magnesium cations and stabilization of the oxide-hydroxide layer. 


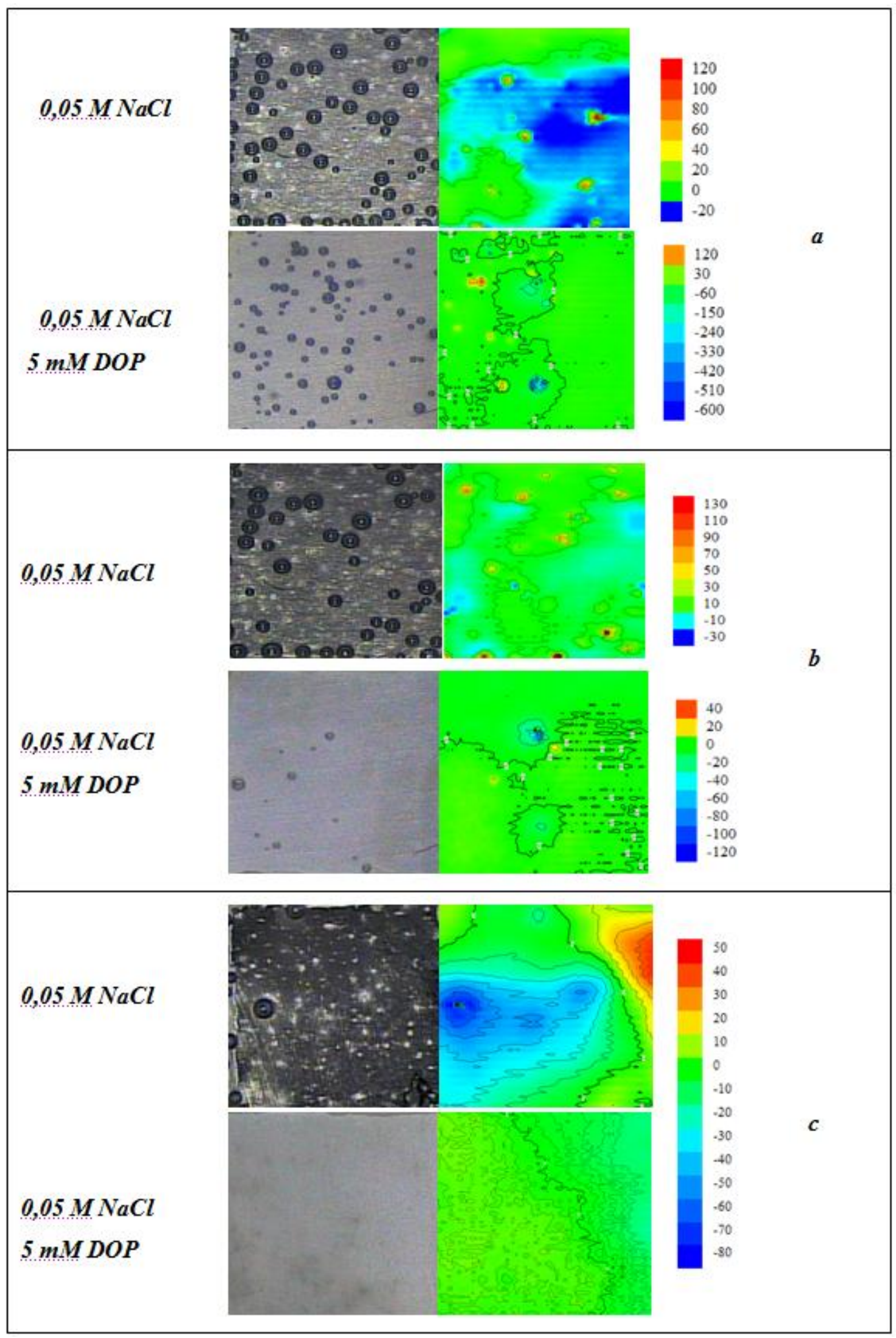

Figure 9. SVET measurements on the surface of WE43 magnesium alloy in $0,05 \mathrm{M} \mathrm{NaCl}$ after: $a-1 \mathrm{~h} ; b-3 \mathrm{~h} ; c-24 \mathrm{~h}$. 


\section{References}

1. F. Zucchi, V. Grassi and F. Zanotto, Sodium monocarboxylates as inhibitors of AZ31 alloy corrosion in a synthetic cooling water, Mater. Corros., 2009, 60, no. 2, 199-205. doi: $10.1002 / \mathrm{maco} .200805045$

2. A. Frignani, V. Grassi, F.Zanotto and F.Zucchi, Inhibition of AZ31 Mg alloy corrosion by anionic surfactants, Corros. Sci., 2012, 63, 29-39. doi: 10.1016/ j.corsci.2012.05.012

3. N. Dinodi and A.N. Shetty, Alkyl carboxylates as efficient and green inhibitors of magnesium alloy ZE41 corrosion in aqueous salt solution, Corros. Sci., 2014, 85, 411427. doi: $10.1016 /$ j.corsci.2014.04.052

4. H. Gao, Q. Li, Y. Dai, F. Luo and H.X. Zhang, High efficiency corrosion inhibitor 8hydroxyquinoline and its synergistic effect with sodium dodecylbenzenesulphonate on AZ91D magnesium alloy, Corros. Sci., 2010, 52, 1603-1609. doi: 10.1016/j.corsci. $\underline{2010.01 .033}$

5. El-Sayed M. Sherif, Effects of 5-(3-Aminophenyl)-tetrazole as a Corrosion Inhibitor on the Corrosion of $\mathrm{Mg} / \mathrm{Mn}$ alloy in Arabian Gulf Water, Int. J. Electrochem. Sci., 2011, 6, 5372-5387.

6. Yu.I. Kuznetsov, A.M. Semiletov and A.A. Chirkunov, Inhibition of magnesium corrosion by triazoles, Int. J. Corros. Scale Inhib., 2016, 5, no. 1, 31-49. doi: $\underline{10.17675 / 2305-6894-2016-5-1-3}$

7. Hongwei Shi, En-Hou Han and Fuchun Liu, Corrosion protection of aluminium alloy 2024-T3 in $0.05 \mathrm{M} \mathrm{NaCl}$ by cerium cinnamate, Corros. Sci., 2011, 53, 2374-2384. doi: $10.1016 / \mathrm{j} . c o r s c i .2011 .03 .012$

8. M.L. Zheludkevich, S.K. Poznyak, L.M. Rodrigues, D. Raps, T. Hack, L.F. Dick, T. Nunes and M.G.S. Ferreira, Active protection coatings with layered double hydroxide nanocontainers of corrosion inhibitor, Corros. Sci., 2010, 52, 602-611. doi: 10.1016/j.corsci.2009.10.020

9. S. Thirugnanaselvi, S. Kuttirani and A.R. Emelda, Effect of Schiff base as corrosion inhibitor on AZ31 magnesium alloy in hydrochloric acid solution, Trans. Nonferrous Met. Soc. China, 2014, 24, no. 6, 1969-1977. doi: 10.1016/S1003-6326(14)63278-7

10. Lihui Yang, Yantao Li, Bei Qian and Baorong Hou, Polyaspartic acid as a corrosion inhibitor for WE43 magnesium alloy, J. Magnesium Alloys, 2015, 3, no. 1, 47-51. doi: 10.1016/j.jma.2014.12.009

11. A.F. Galio, S.V. Lamaka, M.L. Zheludkevich, L.F.P. Dick, I.L. Müller and M.G.S. Ferreira, Inhibitor-doped sol-gel coatings for corrosion protection of magnesium alloy AZ31, Surf. Coat. Technol., 2010, 204, no. 9-10, 1479-1486. doi: 10.1016/j.surfcoat.2009.09.067

12. O.V. Karavai, A.C. Bastos, M.L. Zheludkevich, M.G. Taryba, S.V. Lamaka and M.G.S. Ferreira, Localized electrochemical study of corrosion inhibition in 
microdefects on coated AZ31 magnesium alloy, Electrochim. Acta, 2010, 55, no. 19, 5401-5406. doi: 10.1016/j.electacta.2010.04.064

13. R. Supplit, T. Koch and U. Schubert, Evaluation of the anti-corrosive effect of acid pickling and sol-gel coating ion magnesium AZ31 alloy, Corros. Sci., 2007, 49, no. 7, 3015-3023. doi: $10.1016 /$ j.corsci.2007.02.006

14.F. Zucchi, G. Trabanelli and C. Monticelli, The inhibition of copper corrosion in $0.1 \mathrm{M}$ $\mathrm{NaCl}$ under heat exchange conditions, Corros. Sci., 1996, 38, no. 1, 147-154. doi: 10.1016/0010-938X(96)00121-7

15. Yu.I. Kuznetsov, M.O. Agafonkina and N.P. Andreeva, Inhibition of copper dissolution in water solutions of triazoles, Russ. J. Phys. Chem., 2014, 88, no. 4, 702-707. doi: 10.1134/S0036024414040141

16. Yu.I. Kuznetsov, "Organic Inhibitors of Corrosion of Metals", New York, Plenum Press, 1996, 283 pp.

17. Yu.I. Kuznetsov, N.P. Andreeva and G.Yu. Kazanskaya, On the inhibition effect of dialkyl phosphates in the depassivation of metals, Prot. Met., 2000, 36, no. 4, 351-355. doi: $10.1007 / \mathrm{BF} 02758507$

18. A. Chirkunov, Metal Passivation By Phosphorous-Containing Inhibitors, Proc. Eur. Corros. Congr. 2010 (EUROCORR 2010), Paper 1305. 